\title{
SMART GRID: CONCEPÇÃO DE UM APLICATIVO PARA GERENCIAMENTO INTEGRADO DO CONSUMO DE ENERGIA ELÉTRICA, ÁGUA E GÁS
}

\author{
Alisson Felipe dos Santos (alisson_felipedossantos@yahoo.com.br) - Escola Politécnica,
} Universidade de São Paulo.

Francesco Bordignon (francesco.bordignon@usp.br) - Escola Politécnica, Universidade de São Paulo.

\begin{abstract}
RESUMO
As smart grid já são realidade em diversos países que, com projetos piloto, promovem inovações tecnológicas e desenvolvem modelos conceituais de smart cities, com uso da Tecnologia da Informação e Comunicação (TIC). No Brasil, a smart grid pode gerar benefícios reais para toda a sociedade, e ajudar no desenvolvimento das smart cities e Internet of Things. O objetivo deste artigo é apresentar um modelo conceitual de aplicativo com multisserviços para ser usado pelos consumidores, permitindo uma gestão inteligente e integrada do consumo de energia elétrica, água e gás. E, também promover o consumo consciente e eficiente. Para elaborar o artigo, foi feita uma pesquisa das experiências práticas em projetos de smart grid desenvolvidas no mundo, visando adquirir conhecimentos e, assim, propor melhorias, através de uma proposta de integração, via aplicativo, dos serviços públicos. No modelo proposto, durante a realização da pesquisa, não foram identificados a existência de aplicativos similares, em termos de abrangência, embora, existam realizações na mesma linha. Como contribuições, espera-se atender o mercado brasileiro, pois apresenta aderência aos estudos e práticas de outros modelos desenvolvidos ao redor do mundo. E, também permitir integrações com tecnologias (Big Data, Cloud Computing e Data Analytics), e outros serviços públicos.
\end{abstract}

Palavras-chave: Smart grid; smart meter; smart city; Internet of Things

Área: Potencial da Internet of Things (IoT) e soluções de TIC para o desenvolvimento de produtos e serviços

\section{INTRODUÇÃO}

A smart grid surge como uma forma de mitigar os altos custos para modernização da rede elétrica no Brasil, pois se bem planejada, os investimentos poderiam ser divididos entre as empresas prestadoras de serviço público. Por outro lado, em outros países, as smart grids já estão bem difundidas, visto que empresas de distribuição de energia têm investido na instalação de smart meters, automação, TIC e softwares, a fim de otimizar a operação das redes, tornar os serviços oferecidos mais eficientes, e proporcionar a participação dos consumidores. Por exemplo, o projeto "Linky" desenvolvido pela Électricité Réseau Distribution France - ERDF, já está na segunda fase e prevê até 2021 a instalação de 35 milhões de smart meters, o que corresponde $95 \%$ do território francês; outro projeto, o "Telegestore", uma das iniciativas mais referenciadas mundialmente nesta área, foi desenvolvido entre 2001 e 2006, na Itália, pela Ente Nazionale per l'Energia Elettrica - Enel e instalou mais de 32 milhões de smart meters no território italiano. Hoje, a Enel promove o intercâmbio de informações e compartilha a experiência adquirida, implantando projetos de smart grid na Espanha, na Romênia, na Rússia, no Chile e até no Brasil (na cidade de 
Búzios). E, também desenvolve tecnologias, para smart city, em: smart living e smart mobility (CGEE, 2012).

No Brasil, a smart grid, ainda, caminha a passos mais lentos, porém algumas concessionárias, principalmente, do setor elétrico já iniciaram projetos piloto na área. No entanto, tudo ainda ocorre em baixa escala e de forma descentralizada; de fato, o que pode se tornar uma realidade é a automação das subestações existentes.

O principal objetivo deste trabalho é permitir integração dos setores de energia, recursos hídricos e gás natural, então, foi pensado e desenvolvido um conceito de aplicativo para gerenciamento integrado do consumo de energia elétrica, água e gás, que ainda não existe no mercado e atenda às necessidades do novo mercado que se identifica no Brasil. Com uma proposta de solução inovadora, o aplicativo permitirá atender aos novos hábitos dos consumidores, ao mesmo tempo que contribuirá para melhorias na maneira como os serviços públicos são prestados e disponibilizados para os consumidores, como também no relacionamento entre consumidores e concessionárias.

O conceito, visa, também, contribuir para tornar possível o rateio dos investimentos entre os agentes envolvidos. Além disso, espera-se, no futuro, adotar a solução em outros serviços públicos. Destaca-se, como benefícios intrínsecos do conceito: sustentabilidade ambiental, melhorarias na eficiência energética e econômica (otimização de custos).

A metodologia utilizada é parte de uma pesquisa inicial com base nas experiências práticas em projetos de smart grid desenvolvidas no mundo. Obtidas nos trabalhos de CGEE (2012), Toledo (2012) e Lamin (2013), também incluindo trabalhos mais aplicados desta abordagem, tais como os relatórios de Giordano et al. (2013), Rivera, Esposito e Teixeira (2013), e Andreadou et al. (2016).

Finalmente, espera-se que para construir uma smart grid no país e usufruir, de fato, do conceito do aplicativo proposto e outras soluções, é necessário ter o esforço e participação de diversos agentes trabalhando em conjunto, dentre eles: Governo, agentes reguladores, agentes normativos, empresas geradoras, empresas distribuidoras, indústrias fornecedoras, empresas privadas, instituições de ensino/pesquisa e o próprio consumidor.

O trabalho está estruturado em 6 capítulos. Capítulo 2 apresenta o referencial teórico. Os capítulos 3 e 4 apresentam as tecnologias, e segurança cibernética e privacidade dos consumidores, nesta ordem. O capítulo 5 apresenta o conceito do aplicativo e benefícios, respectivamente. E, finalmente, o capítulo 6 traz as conclusões e trabalhos futuros.

\section{SMART GRID}

De acordo com o U.S. Department of Energy (2009), smart grid é uma visão a ser completada, e que deve ser construída para atender às necessidades e características do mercado que será implementado e levando em conta múltiplas perspectivas, tais como, tecnológica, ambiental, socioeconômica e político-regulatória.

Segundo Lopes et al. (2012), smart grid é a integração das redes de energia, conjugadas às tecnologias da informação e comunicação para criar uma infraestrutura inteligente na energia elétrica que preveja uma evolução contínua de aplicações para benefício do usuário final. Falcão (2009) enfatiza também que o conceito smart grid traz a ideia da utilização integrada e intensiva de equipamentos digitais na rede elétrica, permitindo comunicação dos diversos componentes que, entre outras coisas, permitirá a implantação de sistemas de controle e monitoramento de maneira mais eficiente que os atualmente em uso, bem como otimizar o fornecimento de energia, reduzir perdas de várias naturezas, reduzir tempo de exposição a 
falhas (com self-healing) e dar suporte às aplicações energeticamente eficientes. Além dos fatores anteriormente apontados, é possível prover a informação correta para a entidade correta (concessionárias, consumidores e Governo), no instante correto, para tomar a decisão correta.

Com base nos trabalhos de Toledo (2012) e Rivera, Esposito e Teixeira (2013), o conceito pode ajudar na automação da distribuição, na cadeia de fornecimento de energia, na melhoria dos canais de interação e serviços com o consumidor. Em termos gerais, permite adotar ou criar novos conceitos para viabilizar o crescimento da economia e tem sido fator determinante no desenvolvimento técnico-econômico em diversos países, com aplicação direta no setor elétrico e, também, em outros serviços de utilidade pública.

\subsection{Smart grid no mundo}

De acordo com o trabalho, Smart Grid projects in Europe: lessons learned and current developments, de Giordano et al. (2013) existem atualmente no mundo mais de 200 projetos de smart grid e/ou smart city sendo desenvolvidos, em diversos estágios e complexidade. Alguns projetos possuem o apoio do Governo e outros são desenvolvidos com o envolvimento de diversas empresas que atuam no setor elétrico, setor industrial (eletrônica, telecomunicação e softwares), entre outras. Projetos desta natureza exigem a integração de várias tecnologias, tais como: TIC, smart meters, sensores, equipamentos de monitoramento e segurança cibernética. Estas tecnologias, juntamente com o desenvolvimento de boas práticas que as integrem, permitindo operarem em conjunto, e apenas isso, torna-se a tarefa complexa e propõe desafios técnicos ainda em estágio experimental em diversos países no mundo.

Com o objetivo de promover a colaboração, troca de experiências, boas práticas, uso de novas ferramentas e sistemas, entre os países no desenvolvimento e na coordenação dos projetos de smart grid, em 2011, foi criado o International Smart Grid Action Network - ISGAN que está no âmbito da International Energy Agency - IEA. Participam voluntariamente: Alemanha, Austrália, Áustria, Bélgica, Canadá, Coréia do Sul, Espanha, EUA, Finlândia, França, Holanda, Índia, Inglaterra, Irlanda, Itália, México, Noruega, Rússia, Singapura, Suécia e Suíça. E, outros integrantes convidados: África do Sul, Brasil, China, Dinamarca, Japão e Turquia, entre outros. O quadro 1 apresenta alguns projetos de smart grid desenvolvidos no mundo.

\begin{tabular}{|c|c|c|c|c|c|}
\hline & Nome do projeto & Organização & Descrição do projeto & País & Período \\
\hline 1 & E-DeMa & RWE RWN & $\begin{array}{l}\text { Aumentar eficiência energética, melhorar os serviços públicos e a vida dos } \\
\text { consumidores através do controle da energia pela Internet } \text { em tempo real. }\end{array}$ & Alemanha & $2009-2014$ \\
\hline 2 & Estrela & $\begin{array}{l}\text { Iberdrola } \\
\text { Distribución }\end{array}$ & $\begin{array}{l}\text { Instalação de } 100.000 \text { smart meters e sistema AMM (Automated Meter } \\
\text { Management), para promover a interoperabilidade entre todos os vários fabricantes de } \\
\text { smart meters. }\end{array}$ & Espanha & 2010-2011 \\
\hline 3 & $\begin{array}{l}\text { California Smart } \\
\text { Grid }\end{array}$ & PG\&E & $\begin{array}{l}\text { Implantação de smart grid na Califórnia com a modernização dos medidores dos } \\
\text { sistemas de energia e gás de aproximadamente } 15 \text { milhões de consumidores. }\end{array}$ & EUA & 2006-2011 \\
\hline 4 & Linky Piloto & ERDF & $\begin{array}{l}\text { Implantação do sistema AMM, desenvolvimento do computador lógico "Linky", para } \\
\text { experimento de } 300.000 \text { smart meters e } 5.000 \text { concentradores digitais com } \\
\text { tecnologias PLC, GPRS, LAN e WAN. }\end{array}$ & França & $2007-2011$ \\
\hline 5 & InovGrid & $\begin{array}{l}\text { EDP } \\
\text { Distribuição } \\
\text { AS }\end{array}$ & $\begin{array}{l}\text { Desenvolvido na cidade de Évora instalou dispositivos eletrônicos Energy Box (EB) } \\
\text { com AMM e TIC, para coletar dados e oferecer novos serviços aos consumidores, } \\
\text { como micro geração na rede e aumento da inteligência de serviço da rede. A EDP } \\
\text { também aplicou o conceito em outras localidades no mundo. No Brasil, é a } \\
\text { responsável pelo projeto InovCity, na cidade de Aparecida, em São Paulo. }\end{array}$ & Portugal & $2008-2013$ \\
\hline 6 & Telegestore & $\begin{array}{c}\text { Enel } \\
\text { Distribuzione }\end{array}$ & $\begin{array}{l}\text { Instalados mais de } 32 \text { milhões de smart meters nas unidades consumidoras em escala } \\
\text { nacional. O smart meter instalado possui alarme sonoro para indicar o aumento do } \\
\text { consumo e índice de falhas inferior a } 0,3 \% \text {, também permite gerenciamento remoto } \\
\text { do consumo, medir energia ativa e reativa, transmitir dados e outras funcionalidades. }\end{array}$ & Itália & 2001-2006 \\
\hline 7 & Grid4EU & ERDF & $\begin{array}{l}\text { Testar conceitos e tecnologias inovadoras para ajudar a remover barreiras à } \\
\text { implantação de smart grids. Concentra-se em gerenciar dinamicamente a oferta e } \\
\text { procura de eletricidade, que são cruciais para a integração em larga escala de energias } \\
\text { renováveis e capacitar os consumidores a se tornarem participantes ativos. }\end{array}$ & $\begin{array}{l}\text { Multinacional } \\
\text { (CZ, FR, DE, } \\
\text { IT, ES, SE) }\end{array}$ & 2011-2015 \\
\hline 8 & $\begin{array}{c}\text { Integrating } \\
\text { households in the }\end{array}$ & $\begin{array}{l}\text { Danish } \\
\text { Building }\end{array}$ & $\begin{array}{l}\text { Estudar a integração das famílias na smart grid e desenvolve recomendações. Com } \\
\text { base nos estudos de caso nos países participantes, o projeto contribui com novos }\end{array}$ & Multinacional & $2012-2015$ \\
\hline
\end{tabular}




\begin{tabular}{|c|c|c|c|c|c|}
\hline & $\begin{array}{c}\text { smart grid } \\
\text { (IHSMAG) }\end{array}$ & $\begin{array}{l}\text { Research } \\
\text { Institute, } \\
\text { Aalborg } \\
\text { University }\end{array}$ & $\begin{array}{l}\text { conhecimentos para projetos mais abrangentes. Além das entrevistas e observações } \\
\text { em campo, o projeto inclui estudos técnicos com a interoperabilidade, padrões de } \\
\text { comunicação, etc. As soluções de smart grid estudadas no projeto também contam } \\
\text { com Electric Vehicle (EV), medição inteligente e feedback aos consumidores. }\end{array}$ & $(\mathrm{DK}, \mathrm{ES}, \mathrm{NO})$ & \\
\hline 9 & Meter-ON & $\begin{array}{c}\text { EDSO for } \\
\text { Smart Grids }\end{array}$ & $\begin{array}{l}\text { O projeto é uma ação de coordenação e apoio que visa à orientação de projetos com } \\
\text { soluções smart meter em toda a Europa, através das experiências bem-sucedidas no } \\
\text { campo. Baseada em projetos relevantes de P\&D e projetos piloto em larga escala. }\end{array}$ & $\begin{array}{l}\text { Multinacional } \\
\text { (AT, IT, ES) }\end{array}$ & $2012-2014$ \\
\hline 10 & E-price & $\begin{array}{l}\text { Eindhoven } \\
\text { University of } \\
\text { Technology }\end{array}$ & $\begin{array}{l}\text { Propor um sistema avançado de TIC para serviços auxiliares (reserva de capacidade) } \\
\text { que permite soluções mais inteligente, como incentivos financeiros em tempo real } \\
\text { para adaptar consumo/produção. De acordo com as necessidades do sistema de } \\
\text { energia e gestão da demanda graças à introdução em larga escala dos smart meters. }\end{array}$ & $\begin{array}{l}\text { Multinacional } \\
\text { (IT, NL, HR, } \\
\quad \mathrm{CH})\end{array}$ & 2010-2013 \\
\hline
\end{tabular}

Fonte: adaptado de CGEE (2012) e Giordano et al. (2013)

\subsection{Smart grid no Brasil}

No Brasil, segundo Lamin (2013) os principais motivadores para desenvolver e implantar as smart grids, são: redução das perdas não técnicas, melhoria da continuidade e eficiência energética. No país, já existem iniciativas governamentais e privadas que visam ao desenvolvimento das tecnologias, alterações na regulamentação do setor elétrico nacional e implantação de smart grids através de projetos piloto em algumas cidades brasileiras. Atualmente, 10 projetos estão em fase de implantação e teste nos estados do Amazonas, Ceará, Minas Gerais, Paraná, Pernambuco, Rio de Janeiro e São Paulo. A figura 1 mostra os 10 projetos mais relevantes, dos mais de 200 desenvolvidos no país até 2013 (MCTI, 2014).

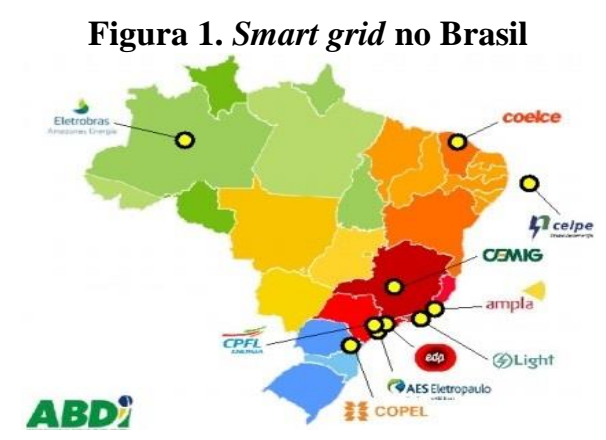

Fonte: ABDI (2014)

Em alinhamento com essas iniciativas, um grupo de trabalho para smart grid da Associação Brasileira de Distribuidores de Energia Elétrica (Abradee), após entendimentos com a Agência Nacional de Energia Elétrica (ANEEL) - parte integrante do grupo de trabalho do Ministério de Minas e Energia (MME) -, realizou alguns estudos com o objetivo de subsidiar projetos sobre o tema. Ainda nessa linha de raciocínio, um plano conjunto ANEEL-BNDESFinep, chamado Inova Energia (IE), também foi criado para apoiar à inovação tecnológica e direcionar os investimentos para modernização dos segmentos de Geração, Transmissão e Distribuição no Brasil (ABDI, 2014).

\section{TECNOLOGIAS}

Para implantar as smart grids será necessário vencer desafios regulatórios, econômicos e financeiros. Além disso, produzir regulamentos específicos sobre o tema e definir as especificações técnicas das tecnologias para atender aos requisitos de cada componente e o mercado de aplicação. No desenvolvimento dos projetos smart grid, tem-se:

\subsection{Telecomunicação}

É a infraestrutura de telecomunicação necessária para criar um ambiente realmente inteligente e atender à hierarquia de dispositivos integrantes da smart grid, pois viabiliza a automação da 
distribuição e para isso o smart meter configura-se como um portal, que realiza a comunicação entre a distribuidora e o consumidor. De um modo geral, pode ser dividida de acordo com a abrangência dentro da cadeia (medidor-concentrador-distribuidora) existente no conceito da smart grid (TOLEDO, 2012).

\subsection{Automação}

De acordo com Lamin (2013), uma automação da rede de distribuição possibilitará atuações remotas, remanejamento de cargas, restauração automática, diminuição das interrupções e reconfiguração de circuitos sem a necessidade de intervenção direta do ser humano. Adicionalmente, proporcionará melhorias na qualidade do serviço prestado aos consumidores, como a redução da duração e frequência das interrupções e falhas, sendo esses os principais benefícios da automação.

\subsection{Tecnologia da informação - TI}

Com base nos trabalhos de Toledo (2012) e Lamin (2013), a TI serve para realizar o controle dos novos equipamentos (smart meter), da telecomunicação e da automação. O uso da TI, fazse necessário para realizar a gestão da informação, o processamento, a análise e o armazenamento de todos os dados produzidos dentro das smart grids. Sem a aplicação de TI, todos os benefícios considerados nas smart grids teriam estimativas menores. Ou, em alguns casos, nenhum tipo de ganho. Ou seja, os sistemas de TI viabilizam diversos benefícios e são extremamente importantes dentro das smart grids.

\subsection{Smart meter}

Segundo Amaral (2014), mesmo com os avanços tecnológicos observados no setor elétrico, os medidores eletromecânicos (analógicos) ainda são os modelos mais utilizados nas residências, e registram basicamente o consumo acumulado de energia, sendo às vezes a sua única funcionalidade disponível. Exigindo que as concessionárias façam a leitura dos valores registrados nos medidores ainda manualmente. Processo esse muito complexo, de alto custo, passível de erros de leitura e imprecisão. No artigo de Aziz et al. (2013), por exemplo, verificou-se que milhões de dólares foram investidos pelas concessionárias de energia elétrica, assim como de água e gás canalizado para desenvolver tecnologias e instalar medidores (smart meters) em toda infraestrutura da smart grid.

Para Arif et al. (2013), smart meter é um dispositivo de medição (digital) com capacidade de coletar dados e disponibilizá-los em tempo real aos consumidores, mantendo-os bem informados em relação ao consumo feito. Adicionalmente, os sistemas com smart meters vêm sendo considerados como uma alternativa efetiva na busca por melhores padrões e também facilitando a gestão do consumo, ou seja, conscientização dos consumidores em busca de um consumo mais eficiente e consciente (LEITE, 2013). A figura 2 apresenta a evolução do medidor analógico para os digitais.

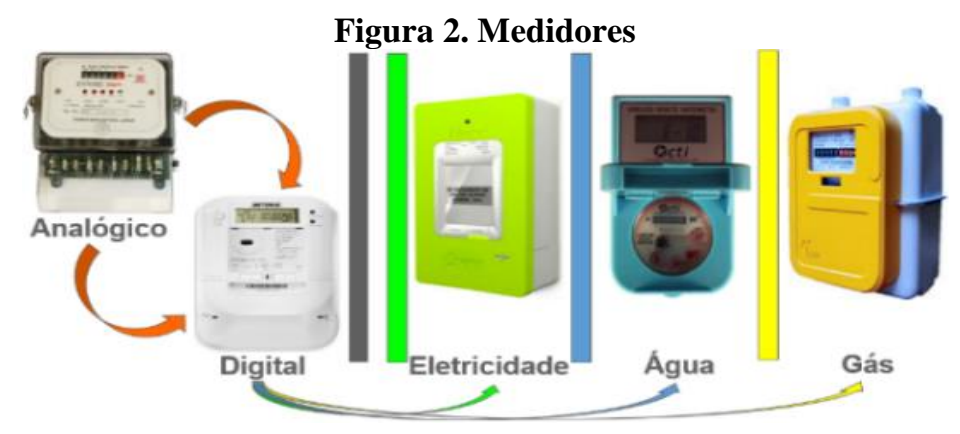

Fonte: elaborada pelo autor (2017) 
Finalmente, para Toledo (2012), smart meter é a base tecnológica para implantação dos conceitos básicos da smart grid e, em geral, o viabilizador técnico-econômico natural, tanto no tocante a benefícios quando a custos agregados, para isso faz-se necessário sua instalação em todas as unidades consumidoras, de maneira planejada, para promover o incremento de novos serviços e melhoria na qualidade dos serviços já prestados.

\section{SEGURANÇA CIBERNÉTICA E PRIVACIDADE DOS CONSUMIDORES}

São os maiores desafios das smart grids, pois é preciso manter a integridade e privacidade das informações ao longo da smart grid, colocando em pauta a natureza pública e privada das informações dos consumidores. Por exemplo, em 2015, na Nova Zelândia levantou algumas preocupações acerca dos smart meters, alegando que eles gravavam e continham informações pessoais (privadas), e que as empresas de energia deveriam adotar uma postura mais aberta sobre o manuseio e tratamento destas informações. Posteriormente, tem-se verificado também preocupações semelhantes nos projetos de smart grid em desenvolvimento na França.

No Brasil, têm-se verificado algumas iniciativas com relação ao assunto, no país já existe a cooperação com institutos internacionais, por exemplo, National Institute of Standarts and Technology (NIST), para definição de critérios e a avaliação dos desafios de segurança cibernética para smart grid, e o mapeamento das principais soluções para criar uma arquitetura de comunicação integrada, que forneça confiabilidade, segurança e privacidade (das informações) dos consumidores (ABDI, 2015).

\section{SISTEMA DE GESTÃO E CONTROLE DO CONSUMO}

O conceito do aplicativo para gerenciamento integrado do consumo de energia elétrica, água e gás, apresenta um conjunto de funcionalidades que foram pensadas para atender às necessidades da população no futuro, ao permitir que os consumidores realizem de maneira integrada a gestão e controle do consumo de energia elétrica, água e gás. Demanda essa que será criada conforme os projetos de smart grid vão sendo desenvolvidos, em escala, nas cidades brasileiras.

De modo geral, mesmo com o desenvolvimento de alguns projetos smart grid no setor elétrico e aplicações de sistemas de monitoramento e controle mais inteligentes na distribuição de água e gás, como também os benefícios proporcionados aos consumidores, concessionárias e Governo, os projetos ainda avançam de forma tímida. Atualmente os medidores de energia não permitem funcionalidades de gestão e controle, a medição feita pelos medidores de água e gás não é precisa e ainda falta aplicar inteligência nos pontos de consumo. Como requerem muito investimento e alto tempo de retorno, ambos fatores inibem o avanço rápido dos projetos de smart grid no Brasil. Além disso, os mercados de energia, água e gás possuem vários players, são totalmente regulados, e as agências reguladoras monitoram os investimentos e despesas para definir as tarifas dos serviços que, na maioria das vezes, contribuem não viabilizando os projetos. No Brasil, existe outra barreira, o modelo de concessões não permite que uma concessionária opere mais de um serviço público, dificultando a sinergia na utilização de equipamentos, como também sistemas de monitoramento e controle.

\subsection{Conceito do aplicativo}

O aplicativo proposto será desenvolvido para dispositivos móveis e para diversas plataformas. O objetivo é permitir que os consumidores dos serviços públicos (energia elétrica, água e gás) façam uma gestão inteligente e integrada, tendo benefícios reais através do gerenciamento e 
controle desses serviços, como economia no consumo ao longo do tempo e, por causa da gestão do consumo, melhorias na qualidade dos serviços prestados, conscientização e eficiência no uso dos recursos naturais.

\subsection{Funcionalidades}

A fim de ajudar os consumidores a controlarem os gastos e gerenciarem os serviços de fornecimento de energia elétrica, água e gás, desenvolveu-se um modelo conceitual das principais funcionalidades do aplicativo que, com comunicação online, permitirá o acesso às informações de consumo de qualquer lugar. O quadro 2 apresenta as funcionalidades propostas.

Quadro 2. Funcionalidades

\begin{tabular}{|c|c|}
\hline Funcionalidades & Descrição do tipo de aplicação \\
\hline Selecionar concessionárias e serviços & $\begin{array}{l}\text { Informando apenas o CPF do titular cadastrado nas contas (de energia elétrica, água e/ou gás), e que } \\
\text { consta no banco de dados das concessionárias, será possível procurar e selecionar as concessionárias em } \\
\text { nível nacional. }\end{array}$ \\
\hline Gerenciar e controlar consumo de energia elétrica & Gerenciar e controlar o consumo de energia elétrica, por exemplo, através da curva de consumo. \\
\hline Gerenciar e controlar consumo de água & Gerenciar e controlar o consumo de água, por exemplo, através da curva de consumo. \\
\hline Gerenciar e controlar consumo de gás & Gerenciar e controlar o consumo de gás, por exemplo, através da curva de consumo. \\
\hline Analisar histórico e diagnosticar sistema & $\begin{array}{l}\text { Analisar histórico do consumo por (hora, dia, semana, mês e/ou ano), acompanhar e monitorar índices de } \\
\text { consumo e obter auxílio ou dicas para reduzir o consumo. Além disso, pode-se usar as ferramentas } \\
\text { avançadas, por exemplo, para monitoramento e controle do consumo, de forma automática, através dos } \\
\text { parâmetros pré-estabelecidos no aplicativo. }\end{array}$ \\
\hline Pagar fatura & Pagar fatura, adicionar crédito, verificar e configurar alertas para pagamento futuro. \\
\hline Obter informações & $\begin{array}{l}\text { Obter informações da conta, por exemplo: ( } \mathrm{N}^{\circ} \text { da instalação, tributos, data de vencimento, etc.), consultar } \\
\text { próprio perfil de consumo, consultar contratos e novos serviços. }\end{array}$ \\
\hline Contatar serviços & $\begin{array}{l}\text { Tirar dúvidas, contatar concessionária, informar mudança de endereço, solicitar auxílio, informar } \\
\text { problemas no fornecimento, enviar mensagens, fotos e vídeos (por exemplo, para informar detalhes dos } \\
\text { problemas de vazamento de água e/ou gás) e caso necessário ligar para um atendente. }\end{array}$ \\
\hline Configurar sistema & $\begin{array}{l}\text { Configurar aplicativo, como: personalizar interface, adicionar e/ou remover funcionalidades, integrar } \\
\text { com outras plataformas, definir metas de consumo, parametrizar controle e monitoramento do consumo. }\end{array}$ \\
\hline Consultar serviços & $\begin{array}{l}\text { Consultar serviços oferecidos, como descontos por meta de consumo alcançada ou pagar menos por } \\
\text { energia, quando usá-la, fora do horário de pico; renegociar débitos existentes; trocar titularidade e alterar } \\
\text { dados (endereço do imóvel). }\end{array}$ \\
\hline Monitorar consumo & $\begin{array}{l}\text { Monitorar os consumos de energia elétrica, água e gás; obter informações estatísticas mais detalhes e } \\
\text { também simular e comparar curvas de consumo (perfil do consumidor x perfil nacional), ou comparar } \\
\text { com o de vizinhos, o que ajuda os consumidores perceberem que tem um consumo elevado ou não. }\end{array}$ \\
\hline $\begin{array}{l}\text { Consultar consumo por equipamento (energia } \\
\text { elétrica, água e gás) }\end{array}$ & $\begin{array}{l}\text { Consultar individualmente o consumo de energia elétrica, água e gás feito por equipamento; fazer } \\
\text { parametrizações do consumo por equipamento (como: obter alertas no aplicativo ou desligá-los } \\
\text { automaticamente quando atingirem um consumo pré-definido); encontrar os vilões do consumo (fontes } \\
\text { de gastos) existentes no sistema, o que auxilia a trocar dos equipamentos no momento certo. }\end{array}$ \\
\hline
\end{tabular}

Fonte: elaborado pelo autor (2017)

\subsection{Benefícios}

O desenvolvimento conjunto de um sistema com interoperabilidade e alta disponibilidade são as principais diretrizes e, também onde se identificam as oportunidades de sucesso no Brasil com os seus benefícios. Espera-se, assim, que os diversos sistemas e padrões existentes "conversem entre si", através de um único aplicativo.

Segundo Toledo (2012), aumentará a quantidade e a qualidade das informações de consumo aos consumidores, ampliando suas possibilidades de acompanhamento, planejamento e controle dos gastos, evitando o desperdício e permitindo um consumo consciente e eficiente.

O consumidor por meio das funcionalidades propostas, por exemplo, poderá acessar e pagar a fatura, encontrar informações da conta e instalação, definir metas de consumo, acompanhar 
detalhadamente o consumo, armazenar as informações consultadas, escolher opções diferenciadas de tarifação durante o consumo e contatar outros serviços oferecidos pelas concessionárias, de forma online e integrada. Além disso, o aplicativo permitirá o gerenciamento e controle do consumo (por hora, semana, mês e/ou ano), configurações e diagnóstico dos dados através da análise dos gráficos de históricos de consumo, entre outras funcionalidades. A figura 3 apresenta algumas interfaces do aplicativo.

Figura 3. Interfaces da gestão e controle do consumo de energia elétrica, água e gás
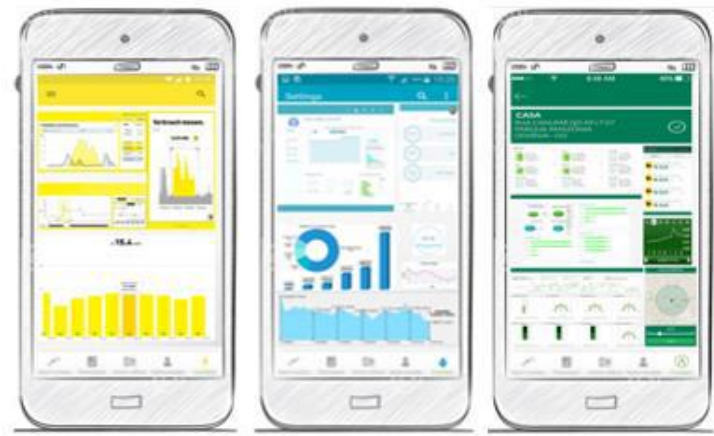

Fonte: elaborada pelo autor (2017)

Através de uma interface amigável com funcionalidades simples e orientadas para o consumidor, com intrínseco foco na conscientização ambiental, pretende-se atender às necessidades dos consumidores, ajudando-os a controlarem os gastos com o consumo dos serviços públicos, pois possibilita o acompanhamento do consumo em tempo real, o que lhes permite saber o quanto foi consumido, diariamente, e o quanto vai ser pago, com antecedência, sem precisar receber a fatura no final do mês. Assim, espera-se aumentar a capacidade intuitiva de gestão e controle, ou seja, aumentar a participação ativa dos consumidores ao proporcionar ferramentas inovadoras, para uma interação efetiva com as concessionárias por meio de um único aplicativo para multisserviços.

Outros benefícios identificados, agora para as concessionárias, são permitir coletar dados e monitorar em tempo real o consumo na área de concessão. Além disso, também proporcionará análises dos dados para previsão e identificação de picos de consumo, otimizando as operações das redes de distribuição e melhorando os serviços prestados, assim como o relacionamento com os consumidores.

Para as prefeituras, ajudará a conhecer os perfis dos consumidores, promover políticas públicas assertivas e eficientes, voltadas para o conceito smart city e, relacionadas ao consumo consciente de energia, água e gás, melhorando o planejamento e investimentos em infraestrutura através do conhecimento dos dados de consumo de cada região, cidade, bairro ou até mesmo rua, de fato, criando um valor coletivo com contribuições para a sociedade, gestão pública, concessionárias, entre outras.

Para o Brasil, auxiliará estrategicamente no desenvolvimento das smart grid, criando uma base para implementação das smart cities e, analogamente, para Internet of Things. De acordo com Toledo (2012), tais benefícios se estendem ainda a outros atores nacionais, como poder público, entidade de pesquisa, indústria e universidades, através da geração de empregos, patentes, teses, produtos e serviços, por certo, promovendo a tecnologia no país, com aprimoramento das soluções e otimização dos investimentos. Adicionalmente, vantagens são observadas pelos consumidores, fornecedores, órgãos públicos e stakeholders que podem usufruir do conceito "smart city", onde os recursos de infraestrutura são aproveitados para oferecer benefícios em outros setores de utilidade pública, por exemplo: segurança, trânsito, etc. De forma complementar deverá minimizar os investimentos para implementação destes. 
Figura 4 apresenta, em três partes, a arquitetura e descrição do conceito do aplicativo.

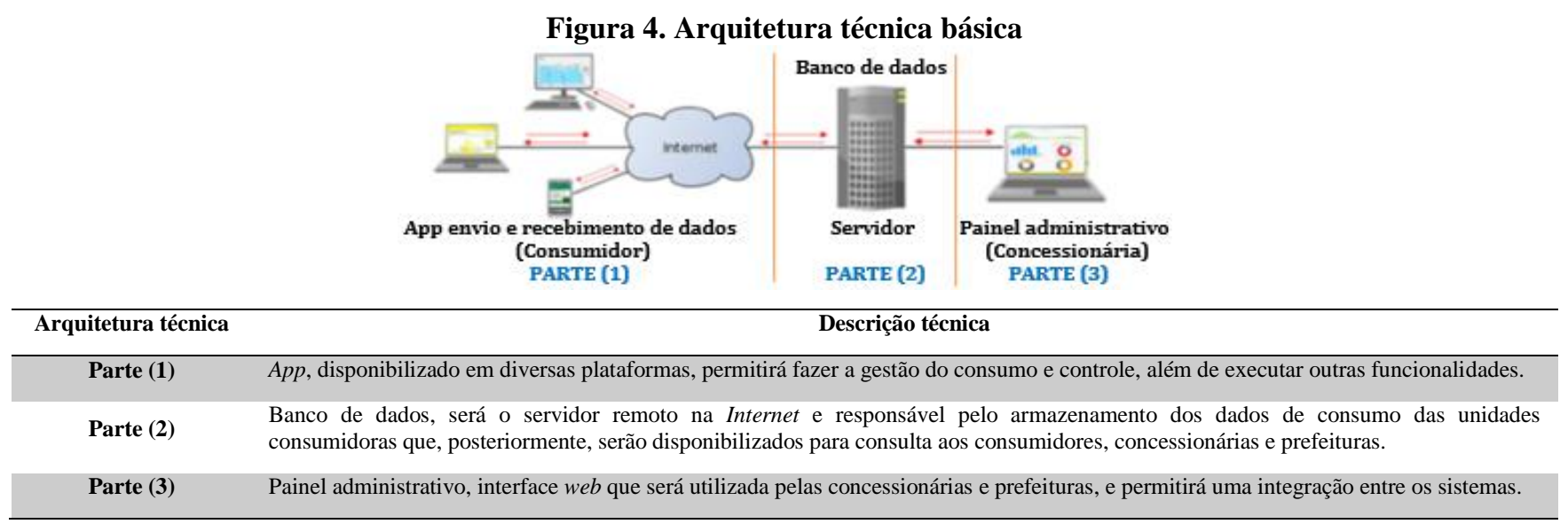

Fonte: elaborada pelo autor (2017)

Nos últimos anos, verificaram-se boas perspectivas em função dos resultados apresentados pelas smart grids, elas foram tão animadoras que as principais cidades no mundo já estão migrando rapidamente para esse novo conceito, principalmente, oferecidos nos serviços públicos. Nesse cenário, o Brasil está integrado às discussões globais sobre o tema e, também, levando em consideração as principais experiências internacionais, tais como: smart homes; conceito "prosumidor", onde o produtor-consumidor pode fornecer energia para a rede; geração distribuída (GD); veículos elétricos (VE) e veículos elétricos híbridos recarregáveis (VEHR); sistemas de armazenamento; painel fotovoltaico e também microgrid.

\section{CONCLUSÕES E TRABALHOS FUTUROS}

A maior parte das pesquisas encontradas na literatura aborda sobre diferentes formas de aplicação da tecnologia smart meter nos serviços públicos, algumas podem ser citadas como referências, porém quase todas tratam a aplicação de maneira isolada, geralmente, no serviço de energia elétrica, água ou gás, às vezes, o melhor exemplo de aplicação, quando existe, aborda a aplicação em dois serviços simultaneamente, por exemplo (energia elétrica e gás), em projetos smart grid realizados nos EUA e na França.

Sob o ponto de vista estratégico, no Brasil seria interessante que as concessionárias já desenvolvessem projetos de smart grid prevendo a integração dos três serviços públicos (energia elétrica, água e gás), ou seja, convergindo-os para uma única solução de multisserviços de valor agregado, criando sinergia nos processos e permitindo que os projetos smart grid brasileiros alcancem a maturidade rapidamente, o que contribui para alavancar o mercado interno e a competitividade internacional do país. Neste cenário, o conceito do aplicativo, ao buscar uma visão inovadora para melhorias dos serviços, pretende agregar tecnologias modernas e propor uma solução completa e abrangente, mostrando-se útil e atendendo às necessidades da sociedade. Portanto, o aplicativo proposto, tem boas perspectivas e grande potencial de ser referência no mercado ao possibilitar benefícios para toda a sociedade, auxílio às políticas públicas e serviços públicos (com colaboração do cidadão) e no desenvolvimento de projetos com soluções integradas.

Para trabalhos futuros, ressalta-se a necessidade de realizar estudos mais aprofundados sobre a integração do aplicativo conceito, apresentado nesse artigo, com outras tecnologias emergentes como: Big Data, Cloud Computing e Data Analytics, a fim de melhorar as funcionalidades propostas, pois ambas tecnologias já são utilizadas, por exemplo, no mundo 
dos negócios, no meio acadêmico e no setor público brasileiro e, assim, criar um aplicativo onde consumidores participem e auxiliem ativamente nas decisões sobre o lugar em que vivem.

\section{REFERÊNCIAS}

ABDI. Mapeamento da Cadeia Fornecedora de TIC e de seus Produtos e Serviços para Redes Elétricas Inteligentes (REI): Normas Técnicas, Padrões e Regulamentos Aplicados à Cadeia de Produtos e Serviços de TIC para REI, TR 01/2013 ABDI - iAPTEL. Brasília, DF - 2014.

ABDI. Redes Elétricas Inteligentes no Brasil: Estratégia do Brasil para acelerar a implantação nas cidades - Estratégias de Governo para desenvolver a "Smart Grid" no Brasil. ABDI Abinee TEC 2015. Brasília, DF - 2015.

AMARAL, H. L. M. Desenvolvimento de um smart meter: um estudo sobre eficiência energética através das redes inteligentes, 2014.

ANDREADOU, N.; et al. Smart Grid Laboratories Inventory 2016, 2016.

ARIF, A.; et al. Experimental study and design of smart energy meter for the smart grid. In: Renewable and Sustainable Energy Conference (IRSEC), 2013 International. IEEE, p. 515520, 2013.

AZIZ, A. F. A.; et al. Artificial intelligent meter development based on advanced metering infrastructure technology. Renewable and Sustainable Energy Reviews, v27, p.191-197, 2013.

CGEE. Centro de Gestão e Estudos Estratégicos. Redes Elétricas Inteligentes: Contexto Nacional. Brasília, DF: Centro de Gestão e Estudos Estratégicos, 2012.

FALCÃO, D. M. Smart grids e microrredes: o futuro já é presente. SIMPÓSIO DE AUTOMAÇÃO DE SISTEMAS ELÉTRICOS, v8, 2009.

GIORDANO, V.; et al. Smart Grid projects in Europe: lessons learned and current developments. JRC Reference Reports, Publications Office of the European Union, 2013.

LAMIN, H. Análise de impacto regulatório da implantação de redes inteligentes no Brasil. 2013. 300 p. Tese (Doutorado em Engenharia Elétrica) - Universidade de Brasília, Brasília, Brasil, 2013.

LEITE, D. R. V. Medidores Eletrônicos: Análise de viabilidade econômica no contexto das redes inteligentes. 2013. 81 p. Dissertação (Mestrado em Engenharia Elétrica) - Universidade de Brasília, Brasília, Brasil, 2013.

LOPES, Y.; et al. Smart Grid e IEC 61850: Novos Desafios em Redes e Telecomunicações para o Sistema Elétrico. XXX Simpósio Brasileiro de Telecomunicações, 2012.

MCTI. Redes Elétricas Inteligentes: Diálogo Setorial Brasil-União Europeia (2014), ENER0001 - $7^{\text {a }}$ CONVOCATÓRIA - Diálogo setorial em redes elétricas inteligentes MCTI Join Research Centre (JRC). Brasília, DF - 2014.

RIVERA, R.; ESPOSITO, A. S.; TEIXEIRA, I. Redes elétricas inteligentes (smart grid): oportunidade para adensamento produtivo e tecnológico local. Revista do BNDES, Rio de Janeiro, n. 40, p. 43-83, 2013.

TOLEDO, F. Desvendando as Redes Elétricas Inteligentes-Smart Grid Handbook. Rio de Janeiro: Brasport, 2012.

U. S. DEPARTMENT OF ENERGY. The Modern Grid: A vision for the Smart Grid, v. 2, 2009. 